\title{
The Role of Historians of Science in Contemporary Society ${ }^{1}$
}

\author{
Joseph Agassi \\ Department of Philosophy, \\ Tel Aviv University \& \\ York University, Toronto \\ E-mail:agass@post.tau.ac.il
}

\begin{abstract}
The famous gulf between the arts and the sciences comes from the current pervasiveness of scientific illiteracy. The resultant increased fragmentation of science threatens scientific research; the resultant increase of the portion of the population of the advanced world that shows general ignorance of science threatens Western culture and democracy, and thus science itself. Historians and popularizers of science can help reduce this gulf. Introducing science historically can help solve many acute social and political problems. Historians of science can try to bring this about.

Discussions of the social role of intellectuals (and of historians of science in particular) require a great deal of a sense of proportion, since most people are still barely educated, hardly familiar with science, much less with its history. Science nonetheless influences lives. Current increased inaccessibility of science boosts the prevailing excessive scientific specialization that scientific and technological progress have imposed. Consequently, the search diminishes severely for comprehensive overviews of the world and even of specific parts of it, leading to disorientation that imperils even the normal functioning of science. There is then a vital need for a search for remedy. Philosophers and historians and popularizers of science can help develop the tools necessary for this vital search.
\end{abstract}

Keywords: amateurs, experts, democracy, history of science, science, science popularization, scientific literacy

Paper read at 'Science as Profession', the $26^{\text {th }}$ Baltic Conference of History of Science on August 21-22, 2014, Helsinki, Finland. 


\section{Introduction}

Most philosophers of science discuss science in the abstract, often applying idealizations that render their works irrelevant to the real world. Historians of science have an advantage here as they may discuss science historically. This by itself may relieve them of many myths without even trying. Here we find a refutation of the myth that deems knowledge in depth and in breadth complementary: knowledge in breadth may dispel myths and thereby facilitate study in depth, and knowledge in depth offers new criteria for studies in breadth; the two approaches are complementary both in achievement and in cooperative progress. This, however, need not be so: the most influential historian of science ever, Thomas S. Kuhn, described normal science quite a-historically, saying periodicals are essential to science, and viewing it as professional-in defiance of familiar historical facts.

The main obstacle to the creation of overviews of science is the idea (or myth) that science is perfect and thus above criticism. The wish to have science errorfree was very valuable. It led Bacon to demand the outright rejection of all uncertain views, especially overviews, in the hope that science and scientific overview evolve securely. He declared all criticism useless. Academic research was stagnant, he observed, since academics refused to yield to criticism. He assumed that this refusal is part of human nature and that academics are hopeless. It turns out that the refusal of criticism is cultural, as attested by improvements that came about, much due to his influence, as the rise of modern science as amateur took place much under his inspiration, and then even academics learned to welcome criticism, as the acceptance of the alternative methodologies of William Whewell and of Karl Popper testifies, since these led to the improved ability to admit error. As the scientific tradition abandoned Bacon's methodology of avoiding proposing hypotheses that may turn out embarrassingly erroneous it tends to favor increasingly greater openness and daring.

This process was impeded by the growth of what Thomas Kuhn called normal science, namely, its unplanned and unsupervised professionalization. This led to the new view of the professional as expert and specialist in parallel to the view of the amateur as dilettante and generalist. It is unclear how Kuhn could ignore the fact that classical science was largely amateur. Professionalization reduced the efforts to make science accessible to the wide public. This permits the return to the professionalism that preceded the scientific revolution. Historians of science can do much to improve the situation and thus possibly rescue science from self- 
damage due to the communication barriers and the consequent replacement of comprehensive views with confusion.

\section{The historian of science}

It is nice to consider the university a place for the intellectually concerned. This is untrue: the aim of most students is to improve their position in the labor market and some faculties are there simply since they were reluctant to leave at the end of their studies. These students should develop intellectual tastes and these faculty members should develop courage. We should help them. Now, however, let us consider the intellectually concerned. Despite the repeated public pronouncement that teaching and study go best hand-in-hand, most academic researchers neglect teaching and most academic teachers neglect research. Those latter are often penalized. This is regrettable. Pressure to publish over-specialized studies lead to over-specialized studies, also in the philosophy and the history of specializations and sub-specializations. The cause of this is desperation, the feeling of inability to contribute otherwise. Their desperation is regrettable and baseless: there is no need for it: curiosity should suffice as a motive for any study. Although guarantee for success in research is impossible, we hope that any piece of self-motivated research may be beneficial. Let us then ignore the desperate and address those who care for the philosophy and the history of science.

Many historians yearn for the past. Their yearning merits respect, yet when it rests on idealization it also merits criticism. Bertrand Russell (1935, p. 12) sympathized with this yearning, noticing a lost coherence of outlook in the distant past. He regretted this loss of past philosophical coherence, yet he avoided yearning for any past. He valued history, faulty and schematic as it surely is, since our very identities are rooted in it—our identities as individuals and as members of societies and of the human race. He found the teaching of every field of study best when undertaken historically. This way he presented the work of scholars as contributions going beyond contemplation, as contributions that signify for us all, as helping us to shape our identities. And, viewing all study as best when put in historical context, we render pivotal the history of thought in general and of science in particular.

For a quick example consider the educational struggle in the USA regarding high-school biology curriculum: should it be Neo-Darwinian or Creationist? 
Such struggles are inherently dogmatic. Were the high-school biology curricula historical, it would begin with Scripture and with Greek ideas, reach Erasmus Darwin's evolutionism and Charles Lyell's creationism, and arrive for more detailed study at Charles Darwin and beyond-indeed, with Creationism as one response to Darwinism. (Agassi, 1983) Alas, teachers are not prepared to teach this way. A number of well-paid projects are devoted to it, but with very little success thus far. The reason for this, let me suggest, is that teachers oppose the idea. Their standard objection to it is that there is no time for history. Experience refutes this objection: the historical approach improves teaching in both efficiency and quality as it shifts discussions from belief in the ideas presented in the classroom to their critical assessment.

Still, the historical approach is unpopular despite its advantage. What can be done, then? I do not know, but here is a viable option: if some critically-minded and concerned American historians of biology would write a historical introduction to it, then their work might become popular. And then the historical approach may infiltrate the classroom and render the redundant controversy obsolete.

In this juncture we may find the reason why the philosophy of a field and its history go hand-in-hand: they share the appetite that we all have for coherence, for some integrated view of the world: integration brings its student nearer to philosophy, as philosophy comes to meet this appetite for the universal. And history of progress in science-any science-is the history of us having fallen short of our ideals, and of our having overcome these obstacles to getting closer to some coherent, integrated view of our world, known as first principles.

\section{First principles}

Traditionally, the first principle of every field of study was the chief item of its philosophy. It was called its metaphysics. There are terminological exceptions, though. The metaphysics of biology is called meta-biology these days, akin to the current terms meta-science and meta-philosophy. The metaphysics of the social sciences is called philosophical anthropology (by mistake, but let us ignore that here; see Agassi, 1977, pp. 24-26). The metaphysics and the history of history is called historiography, namely the rules for writing a history. First principles allegedly generate for a comprehensive overview and guidelines for research. The influence of Sir Francis Bacon on the scientific revolution in opposition 
to metaphysics grew. Much later, with the rise of the influence of Ludwig Wittgenstein, the opposition became an uncompromising principle-allegedly of logic. This principle, that all metaphysical assertions are muddled, has met with severe criticism (of Bertrand Russell, Karl Popper and Willard Van Quine, see Hanfling, 1996). Unable to respond to it, Wittgenstein's disciples gave up his principle, and his playing an intellectual policeman. Giving up Wittgenstein's opposition to metaphysics that allegedly rests on logic, they returned to the earlier opposition to metaphysics of Ernst Mach of just before the revolution in physics, which rested on Bacon's methodology: Mach said, his worldview was nothing but the sum-total of all the sciences extant in his day (Mach, 1894, 38n; cp. Mises, 1930). He is one of the few fortunate individuals who contributed significantly to a few fields of study. But even he could not put all knowledge together and judge it for its consistency. The wish to possess some rounded knowledge leads lesser scholars to seek some basics of the diverse fields of study. Here the word "basics" denotes metaphysics, good or not as the case may be. Averse to metaphysics, Mach replaced it with history. His History of Mechanics (Mach, 1883) made history in and of itself, as in it he undertook a search for a comprehensive scientific worldview.

It behoves friends of metaphysics to admit that in the study of basics we often omit challenging details, thereby depriving profound studies of their depth. This holds for most popular science and for most histories of science. Authors in these fields have to decide what item they can omit and what not. Unfortunately, most historians decide such matters on anachronistic grounds (Agassi, 2008). This renders their studies flat.

Consider the dinosaurs. Biologists, especially paleontologists, know much more about dinosaurs than amateurs like myself. What we all know is that once dinosaurs inherited the earth and then they vanished. This piece of paleontological knowledge is of the greatest practical value, since intuitively it supports the claim of environmentalists that may be vital for our very survival. Perhaps we need no philosophy here, Creationist objections to it notwithstanding. So let me take a more sophisticated significant case. Newtonian mechanics is still taught and applied although it was superseded over a century ago (by Einstein's 1905 studies of relativity and of quantum mechanics). This concerns philosophers of science most. Its impact on the writing of the history of physics is enormous, since historians of science used to express contempt for defunct theories such as the theory of phlogiston, yet they cannot possibly express contempt for Newtonian mechanics. So they either deny that it is defunct or grant it special status. Either 
way, it is a philosophical headache. Let me skip this here as too involved, except to say that the phlogiston has undergone rehabilitation repeatedly, beginning with the study of Hans Christian Ørsted of nearly two centuries ago, yet contempt for it lingers (Agassi, 2008, pp. 482-500).

Rapid technological progress generates radical changes in daily lives and defies conservative attitudes. This way highly sophisticated science increasingly influences everyday life while evading public grasp, casting an acute sense of alienation and a deep yearning for simple integrative ideas and simple social settings with services, they tell us, that traditional communities have provided. These stories are utopian. Understandably, they intensify frustration. Nevertheless, the yearning remains, seemingly because it rests on a principle. That principle is almost within our grasp but annoyingly it eludes us still.

This is no news; it is indeed traditional. The analytic school that follows Wittgenstein dismisses this kind of talk. It still is standard paraphernalia in the philosophical school that is known as Continental philosophy. Its grand old master is Martin Heidegger, the arch-reactionary, indeed the Nazi. He viewed science as intellectually vacuous science-based technology. His follower HansGeorg Gadamer confessed in his autobiography to finding more of interest in Aristotle's Physics than in any modern physics text (Gadamer, 1985, Appendix, pp. 178-193). He was not serious, of course, or else he would have also told us what his attitude was towards ancient scientific texts-of Archimedes, for example. On Floating Bodies of Archimedes comes to settle a disagreement between Plato and Aristotle. Plato claimed that buoyancy is gravity smaller than that of the environment of the buoyant. In Aristotle's physics, buoyancy is levity, an essential quality opposed to gravity. Aristotle declared Plato confused on levity. Archimedes proved the opposite. Classicists still follow Aristotle (Agassi, 2008 , p. 233), in oversight of the very possibility that the history of science has wider bearings.

They have a point, though, and it is significant: tradition takes the history of art and the history of science as totally different matters. Paul Feyerabend said, the gulf between the arts and the sciences rests on education: ordinary educated Westerners are more familiar with the history of art than with the history of science. Is this true? 


\section{The gulf between the arts and the sciences}

The chief cause of the gulf between the arts and the sciences is the inaccessibility of mathematics: ordinary literacy suffices for the ability to read poetry but not even the simplest items of science mathematically expressed. Paleontology and literature differ from genetics and economics in their accessibility to common citizens. The need to render mathematical literacy more common is thus urgent. I will not discuss it here, as it is a vast topic. The pioneering studies of Imre Lakatos show the way, as I have argued elsewhere.

Even without the great help that Lakatos has provided, something can be done. At times we may circumvent mathematical illiteracy. Boyle's law says that the dependence between the pressure and density of air is linear. The ignorant of linearity who fail to understand this will understand it spelled out: twice the air in a tire is twice the pressure in it, thrice the air is thrice the pressure, and so on. This possibility to circumvent mathematical illiteracy is limited. People often show aversion at mathematical formulae even when they see mere hints of them. This aversion demands cure, an educational cure, as its cause is educational: it was absent in the eighteenth century. It (the revulsion to mathematics) began in the nineteenth century when science stopped being a matter for general consumption, for amateur audiences, and became the property of professionals, mainly engineers. The aversion is thus due to the contempt for working people that snobbish education cultivates. An educational reform required for the overcoming of this snobbery can alter our system. That will narrow the gulf considerably - but not fully. If Feyerabend was right, then we still need popular history of science akin to popular history of art.

Already C. P. Snow (later Lord Snow) presented the gulf between the two cultures, the arts and the sciences, as a matter of education. The point of his famous lecture The Two Cultures and the Scientific Revolution (Snow, 1959) was his claim that Soviet education was best, as there the gulf between the arts and the sciences is narrowest. He recommended that the British educational system emulate the Soviet. In his presentation of the split of our culture into two he referred first to the ignorance of the general public of physics and of engineering and then to the segregation of the elites: a British scientist, he asserted, is more likely to communicate with an American scientist than with a British artist. I do not know if this is true. The empirical evidence that Snow had concerns ColdWar international cooperation on nuclear armament; the currently available information on the matter concerns the general public, not the elites. Snow 
accused the artistic elite for the inadequacy of the scientific literacy of the general public - he called them natural Luddites. As tools for the improvement of the public level of scientific literacy he offered educational reform and teaching the history of science. Feyerabend seemed to have agreed.

Scientific literacy — or some level of mathematical proficiency, as you will-is imperative. Cyril Northcote Parkinson noticed in his famous Parkinson's Law (Parkinson, 1957) ${ }^{2}$ that ignorance of the basics of science insure that political and economic decisions are made not by decision-makers but their staff. Specialized scientific advisers to politicians write unread reports. The level of responsibility that accompanies crucial political decisions has thus dropped to a dangerous level. This is not specific to science as the story of diplomat George Keenan's 1946 long telegram illustrates. (Frustrated by having his reports unread, he sent one as a telegram.) Yet scientific reports are special, as they are becoming increasingly important and increasingly unreadable.

Also, scientific literacy matters both politically and scientifically. Galileo and Einstein viewed as viable only scientific items that are popular and accessible to the inexpert. It is hard to say why, but we do feel that limiting knowledge to specialists will not do. Perhaps it is mere suspicion: experts have misled the community more often than not. Perhaps demanding of the public at large informed consent to the specialists will reduce gullibility. A well-informed public is still the only bulwark of democracy. The possibility of such informed consent is waning before our eyes with the decline of interest in science as intellectual and with the rise of the view of it as sheer technology. The danger to science nowadays is then in its losing its intellectual relevance, giving way to the authoritarian rather than the critical stance. The same holds for the arts: avantgarde artists disseminate artistic literacy and leading scientists should do likewise. The inexpert cannot and need not catch up with the expert-in the sciences or in the arts-but popularization amounts to repeated vigilant efforts to bring them closer to each other.

Parkinson's law was first published in the newspaper The Economist on November 18, 1955. 


\section{For the love of science}

We repeatedly ignore the obvious regarding the following distinctly different contrasts: that they are even so plainly distinct.

expert : dilettante :: professional : amateur :: certified : uncertified

Scientific research could hardly become professional before the industrial revolution, as before that scientific research was hardly profitable and sciencebased technology hardly existed. As to members of other professions, some of them can hardly ever be experts (consider astrologers and investment advisers); others develop expertise only when society demands of professionals to be expert, usually by demanding certification; it is a matter of the law of the land; and it hardly ever can have full success. As to research, there is usually no legal need for certification for gainful employment in it; employers often demand it nevertheless.

Scientific literacy, like any literacy, is a matter of degree. Thus far only scientific experts have to show mathematical literacy, but the level of this literacy is going down as specialization proliferates. What and how can historians of science contribute to scientific literacy? This question is hard to answer without some idea about the history of science as such, or even about history as such. There are good and bad reasons for the study of history. Much of the interest in the past is due to hankering after the past, to the nostalgia that fortunately does not hold for the history of science. For, nostalgia is backward-looking and science is progressive. This explains the regrettable neglect of history in the Age of Reason. This holds particularly for the history of science, and for a strong ideological reason. The popular expression of Bacon's idea that scientific theories evolve inductively out of collections of factual information was his apt phrase for them: "just histories of nature" (echoing the term "historia naturalis" of Pliny the Elder, meaning natural science). Bacon's theory of science is just this: science and its history are one. This led him and his followers to the style of writing scientific essays as parts of diaries. In social anthropology, for example, this style lingers. It began to wane in the natural sciences in the mid-nineteenth century, when authors moved increasingly to the dialectic style, to discussions of problems. The last to follow this tradition there was Michael Faraday, whose private diaries largely appeared as papers presented to the Royal Society of London and published in its Proceedings. Yet he did not hide his difficulties and he increasingly expressed dissent from his peers. His great follower James Clerk Maxwell admired his style for its freshness but recommended not to 
emulate him: ceasing to view the inductive style as a just history, Maxwell viewed it as a convention that helps communication of empirical information.

The first professional historian of science was a Baconian George Sarton. His description of the role of historians of science is disappointing: they should add to significant items in the up-to-date science textbook the names of their originators and the dates of their publication and may adorn this with anecdotes that humanize the image of science. Sarton's contemporary, Lynn Thorndike was a student of mediaeval culture interested in the role of magic in it. His study of magic differs from studies in social anthropology except that he shared Sir James Frazer's view of magic as pseudo-science. He published a multi-volume, utterly unreadable history of science and magic (Thorndike, 1923-1958). In a sense this is as odd as the claim that errors in probability such as those that appear in a famous report (Tversky \& Kahneman, 1981) belong to the history of mathematics. Yet it allowed historians to add to the history of science the first buds of the critical attitude, and so of scientific criticism.

\section{Scientific research as dialectic}

A great deal of Newton's Principia is devoted to criticisms of Descartes' theory. Surely it merits more attention than, say, Kant's criticism of the spiritualism of Swedenborg. Nevertheless, Thorndike ignored it; rather he echoed the remark of John M. Keynes, Newton was "the last of the magicians" (Keynes, 1978) which refers to Newton's alchemy. Historians of science neglected Newton's scientific and other texts until Alexandre Koyré (1965) published his terrific, careful studies of them.

What is the place of criticism within science? Even those who reject Popper's 1935 view of science as dialectical —as series of explanatory conjectures and attempts at their refutations-must concede that criticism within science is important. This concession is already half of the methodology of Karl Popper who viewed all openness to criticism rational (Popper, 1945, Ch. 24). Bacon rejected dialectics as futile: he noted the traditional dogmatic refusal of academics to admit criticism. Hence, he suggested, it is better to eschew all doubtful opinion and start afresh. The scientific tradition could not fully endorse Bacon's ban on debates but it did limit the publication of controversial material. Some periodicals still do so, even in the history of science. 
The reason for this is, of course, the identification of science with reason and reason with proof. Even Faraday accepted this idea despite his rejection of Newton's views (that he did most reluctantly). Kelvin and Maxwell, his chief followers, tried to square his speculations with those of Descartes, Newton, and Boscovich. They failed, of course. This became obvious only in 1905. Einstein departed then from the Newtonian heritage and published two papers that conflict with each other, one declaring light to be waves and one declaring it to be particles. Both showed their predecessors to be good approximations. This allows historians of science like Koyré and like his predecessor E. A. Burtt to break from the splendid isolation of science and consider it a part of culture that shares the quality of imperfection with all other human output.

\section{Integrating science within culture}

The first historian to try to present an image of science as integrated within culture in accord with a simple theory of all human knowledge was the notorious Boris Hessen, who attempted to apply the crude view of Marx on the economic base of all knowledge to the paradigm-case of science in his The Social and Economic Roots of Newton's Principia (Hessen, 1931). This study won constant attention despite its obvious poverty because, I suggest, it is an effort to plant science within culture. The introduction of the critical attitude to scientific method does that better, in much more proliferate a manner, and while raising much less opposition.

Historians of the physical sciences influenced by Koyré are busy writing histories of science dialectically_in efforts to show how criticism makes easy to comprehend the details of scientific progress that others find inscrutable and open new avenues for research. For example, Ørsted's discovered electromagnetism (electric direct currents deflect magnetic needles in their vicinities) in 1820 after over two decades of struggle; he left a fairly detailed record of his struggle (Ørsted, 1920). It is hardly studied. My 1962 study of it (Agassi, 2008, II, \$17) is the only one that raises the question - what took him so long? The discovery was so shocking it left him in a daze for three months before he published it (privately). Why was it so important? These questions (and my answers to them) are still ignored. Possibly, the reason is that such questions do not belong to traditional histories of science. But then there are untraditional histories that come from the camp of the continental philosophers, as these try to adopt as much of science that they 
can into their own heritage. An example is the attempt of Brain et al., 2007 to integrate the ideas of Ørsted with its cultural background. I will not discuss it except to point out that it ignores all of these questions, as posing them already makes Ørsted imperfect.

Historians of culture or of science who are not deterred by mathematical formulas may write the history of science as the history of an imperfect yet noble and daring part of Western culture. They may then study the interactions of science with its intellectual and social environments. A poor example that is still laudable as pioneering is Richard Foreman's study (see Kojevnikov et al., 2011). It still is too marginal, since most of his paper is independent of his thesis and its interest lies within the domain of the history of science rather than of culture. The standards practiced in the literature on the history of culture are higher than in the history of science. It is high time for the latter to catch up with the former. The former contains regular expressions of respectful criticism and the latter does this infrequently; the former crosses freely boundaries of subject-matter and the latter is too specialized; the former takes for granted the rationality of interesting errors and the latter dodges such cases. Open discussion will introduce the study of science to people interested in culture: it is impossible to study any part of a culture reasonably while ignoring its impact on culture at large. The same holds for science-when deemed ideas and not only grounds for technology. The greatest result that the study of the history of science can bring to our culture in general is that the history of science is the history of problems, conjectures and their criticisms, as is best described in the works of my teacher Karl Popper (1959, Preface to the English edition).

For better and for worse, science is part-and-parcel of culture. For better it brought about modern thought and liberalism and the industrial revolution. For worse, much worse, it helped in the process of destruction that characterizes the terrible first-half of the twentieth century. The terrible devastation in Hiroshima and Nagasaki showed what devastation we can achieve and the more terrible devastation in Auschwitz showed us what devastation we may be ready to achieve; these two lessons united and led to the counter-culture of the 1960s; they may yet cause the demise of humanity and even of life on this earth. The robustness and optimism associated with science are parts of its tradition. We are banking on it with no notice of the recent great changes that put this optimism into question. We still ought to cling to optimism, but we can no longer be as naïve about it as the Age of Reason was when its thinkers took it for granted that progress is inevitable. 
Science was then ideologically and practically largely amateur; these days it is professional — with the notable exception of popular science and popular histories of science that are often exciting contributions. It is hard to assess their value in general, but it seems it must be tremendous. Einstein has shown repeatedly that we can learn about systems when we consider them under extreme conditions. So consider an extreme professionalization. When we are all as narrow professionals as possible, we lose the ability to speak across professions and this is the end of culture. We are nearing that state. The warning signs are posted. The absence of communication between medical sub-professions kills patients. Recognition of this has led to the reinstatement of general family medicine-not as the traditional absence of specialization but as a new expertise. The absence of communication between the different arms of the military of the United States of America even concerning their space programs led to the loss to the Soviet Union of the race into space with Sputnik. This shocked Americans, and as a remedy the USA administration established NASA as its unified space program. On that occasion, the USA administration also supported programs in the history of science as a means for preventing such error in the future. I do not know how successful this move was, but it could hardly do any harm. Anyway, all this gives us an inkling of the immensity of the dangers that professionalization might incur. Professionalization is obviously welcome, but we must reduce its costs as science may lose all due to its understandable narrowing down and endless splitting. Historians of science as well as historians of culture — and both together at best—can come to help as their professions are parasitic upon other professions. They may take for granted that science is a part of culture that interacts with other parts of it for better and for worse, that they should disseminate minimal mathematical and scientific literacy and develop the genre of popular science. We may hope that this will reduce the gap between the arts and the sciences as well as between professional and amateur. This can only improve matters.

\section{Conclusion}

If we need authorities to lean on, let me mention this. Einstein $(1936, \$ 2)$ said, "The whole of science is nothing more than a refinement of everyday thinking." Ernst Gombrich (1960, pp. 148, 222) said, fine art is common artisanship refined. Yehudi Menuhin (1986, p. 121) said, "I would hate to think I am not an amateur. An amateur is one who loves what he is doing. Very often, I'm afraid, the professional hates what he is doing. So, I'd rather be an amateur." 


\section{References}

Agassi, J. (1977), Towards a Rational Philosophical Anthropology, The Hague: Martin Nijhoff. http://dx.doi.org/10.1007/978-94-010-1095-5

(1983), 'Science in Schools,' Science, Technology Human Values, vol. 8, pp. 66-67. (2008), Science and Its History: Reassessment of the historiography of the science, Boston Studies in the Philosophy of Science, vol. 253, Dordrecht: Springer. http://dx.doi.org/10.1007/978-1-4020-5632-1

Brain, R. M.; Cohen, R. S. \& Knudsen, O., eds. (2007), Hans Christian Ørsted and the Romantic Legacy in Science: Ideas, Disciplines, Practices, Boston Studies in the Philosophy of Science, vol. 241, Dordrecht: Springer. http://dx.doi.org/10.1007/978-1-4020-2987-5

Einstein, A. (1936), 'Physics and Reality,' Journal of the Franklin Institute, vol. 221, no. 3 (March), pp. 31-347. http://dx.doi.org/10.1016/S0016-0032(36)91047-5

Gadamer, H. G. (1985), PhilosophicalApprenticeships, transl. by D. R. Sullivan, Cambridge, MA: MIT Press.

Gombrich, E. H. (1960), Art and Illusion: A Study in the Psychology of Pictorial Representation, London: Pantheon Books.

Hanfling, O. (1996), 'Logical positivism,' in S. G. Shanker (ed. Philosophy of Science, Logic and Mathematics in the Twentieth Century, London: Routledge, pp. 193-194.

Hessen, B. (1931), 'The Social and Economic Roots of Newton's Principia,' in N. I. Bukharin (ed.) Science at the Cross Roads. Papers Presented to the International Congress of the History of Science and Technology, 1931, by the Delegates of the U.S.S.R., London: Frank Cass, pp. 151-212.

Keynes, J. M. (1978), Newton, the Man. The Collected Writings of John Maynard Keynes, Essays in Biography vol. 10, ed. by Elizabeth Johnson, London: The Royal Economic Society. http://dx.doi.org/10.1017/UPO9781139524230.041

Kojevnikov, A.; Carson, C. \& Trischler, H., eds. (2011), Weimar Culture and Quantum Mechanics: Selected Papers by Paul Forman and Contemporary Perspectives on the Foreman Thesis, London: Imperial College Press.

Koyré, A. (1965), Newtonian Studies, London: Chapman and Hall. http://dx.doi.org/10.4159/harvard.9780674181861

Mach, E. (1883), Die Mechanik in ihrer Entwickelung, Leipzig: F. A. Brockhaus. (1894), The Analysis of Sensations and the Relation of the Physical to the Psychical, transl. by C. M. Williams, La Salle: Open Court.

- (1960), The Science of Mechanics: A Critical and Historical Account of Its Development, transl. by T. J. McCormack, La Salle: Open Court.

Menuhin, Y. (1986), Life Class, ed. by Christopher Hope, London: William Heinemann. 
von Mises, R. (1930), Über das naturwissenschaftliche Weltbild der Gegenwart: Rede, Berlin: Preuss. Dr-u. Verlag-AG.

Ørsted, H. C. (1920), Naturvidenskabelige skrifter 1.-3.: samlet udg. med to afhandlinger om hans virke ved Kirstine Bjerrum Meyer, København: Høst \& Søn.

Parkinson, C. N. (1957), Parkinson's Law and other studies in administration, Boston: Houghton Mifflin.

Popper, K. (1945), The Open Society and Its Enemies, London: Routledge.

— (1959), The Logic of Scientific Discovery, London: Hutchinson.

Russell, B. (1935), Religion and Science, London: Thornton Butterworth.

Snow, C. P. (1959), The Two Cultures and the Scientific Revolution, Cambridge: Cambridge University Press.

Thorndike, L. (1923-1958), A History of Magic and Experimental Science, vols. 1-8, New York: Columbia University Press.

Tversky, A. \& Kahneman, D. (1981), 'The Framing of Decisions and the Psychology of Choice,' Science, New Series, vol. 211, no. 4481(Jan 30), pp. 453-458.

Joseph Agassi, FRSC studied in a rabbinical school, in the Hebrew University of Jerusalem (MSc in physics) and in the University of London, where he was assistant to Karl Popper (PhD in general science: logic and scientific method). He was a parachute instructor in the Israeli Defense Force. He is professor emeritus in Tel Aviv University and in York University, Toronto. He has edited about ten books and authored about twenty, and over 500 contributions to the learned press. 